\title{
Telling Active Learning Pedagogies Apart: from theory to practice
}

\author{
Kelsey Hood Cattaneo*(1) \\ The New School University (EEUU) \{hoodcattaneo@newschool.edu\} \\ Received on 16 February 2017; revised on 16 March 2017; accepted on 27 March 2017; published on 15 July 2017
}

DOI: 10.7821/naer.2017.7.237

(c))BY-NC-ND

\begin{abstract}
Designing learning environments to incorporate active learning pedagogies is difficult as definitions are often contested and intertwined. This article seeks to determine whether classification of active learning pedagogies (i.e., project-based, problem-based, inquiry-based, case-based, and discovery-based), through theoretical and practical lenses, could function as a useful tool for researchers and practitioners in comparing pedagogies. This article classified five active learning pedagogies based on six constructivist elements. The comparison was completed through a comparative analysis and a content analysis informed by a systematic literature review. The findings were that learner-centeredness is a primary goal of all pedagogies; however, there is a strong dissonance between each pedagogy's theoretical underpinnings and implementation realities. This dissonance complicates differentiating active learning pedagogies and classification as a comparative tool has proved to have limited usefulness.
\end{abstract}

KEYWORDS: PROJECT-BASED, PROBLEM-BASED, INQUIRY-BASED, CASE-BASED, DISCOVERY-LEARNING

\section{INTRODUCTION}

Families, teachers, administrators, academics, and policy makers are continuously looking for approaches to increase student learning. The tools they use to accomplish this goal include: setting higher standards, developing new curricula, challenging current methods and pedagogies, to quote but a few. While not new, promotion of active learning pedagogies is gaining momentum in the academic literature and policy arenas as a viable solution for increased student achievement. The Finnish National Board of Education has required, for example, that all primary and secondary school subjects in at least one classroom period be taught through the active interdisciplinary, "phenomenon based" learning pedagogy, by the end of 2016 (Finnish National Board of Education, 2015). Even authors in the cognitive science discipline suggest that classrooms with an active learning approach can increase student motivation, knowledge retention, and content transferability (Michael, 2006; Norman and Schmidt, 1992; Vosniadou, Loannides, Dimitrakopoulous, \& Papademetriou, 2001). However, it is almost impossible to understand what an "active learning pedagogy" is from the education literature, as the term is used to describe methods and philosophies alike (Prince, 2004).

*To whom correspondence should be addressed:

The New School

66 W 12th Street, New York, NY 10011, USA
Even more problematic is comparing, contrasting, and evaluating said theories in practice.

This article seeks to determine whether classification of active learning pedagogies would be useful in comparing and contrasting pedagogies, in theory and practice. Through two distinct lenses, theoretical and practical, this article looks at five distinct active learning pedagogies: Problem-based; Discovery-based; Inquiry-based; Project-based; and Case-based learning. The theoretical study is presented as a comparative analysis informed from a traditional literature review. The five pedagogies are compared based on constructivist traits that are described in the literature as integral to their theory.

To provide a second, more practical lens, a systematic literature review was conducted using the abstracts from a different set of articles which is presented through a content analysis. New articles were selected that focused on self-identified examples of active learning environments in practice. These descriptions were then compared against the constructivist traits used in the comparative analysis and similarities and distinctions were noted between the theoretical and practical explanations. The final section of this paper provides a discussion of the usefulness of classifying active learning pedagogies, using elements of constructivism as markers for comparison, and where research can go from here.

\section{RESEARCH METHODS}

Using evidence presented in case studies and quantitative research to develop theories in education, is a mode of research that aims to move past theory defining to construction (i.e., theory building literature see Hoon [2013], Locke [2007] or Eisenhardt and Graebner [2007], amongst others, for a discussion on this subject). To take steps towards theory construction this article looks at the discourses surrounding each active learning pedagogy in the literature, both theoretical and practical, through two lenses and contrasts those descriptions. By approaching active learning pedagogies through an inductive and deductive lens, this article seeks to provide a more comprehensive picture of active learning pedagogies to possibly define and classify each pedagogy to make research and findings more generalizable.

\subsection{Literature Review and Comparative Analysis}

In section 3, a traditional literature review is presented through a comparative analysis of five active learning pedagogies. Key articles on active learning pedagogies as theories were selected and described. The descriptions of five pedagogies were classified on 6 elements which represent comparative indicators identified as 
being emblematic of the constructivist epistemology where active learning pedagogies belong: learner-centeredness (i.e. knowledge creation over knowledge provision); the focus on process and content; interdisciplinary lessons; collaborative lessons; a focus on student reflection; and the importance in intrinsically motivating student work as depicted by a lack of focus on assessment.

The identifiers were quantified based on whether the article explicitly described the constructivist element as an integral part of the pedagogy ("important") with a value of 3 , named the element but did not define it as essential to the pedagogy ("discussed") giving it a value of 2 , or did not specifically reference the element ("not important"), which was assigned zero points. The articles were double coded with an initial interrater reliability of $75 \%$. After consulting the supportive coder, differences in coding were resolved by recoding the articles on the basis of a consensus code, arriving at the results presented in Table 1.

\subsection{Systematic Literature Review and Content Analysis}

Section 4 describes the process of a systematic literature review and subsequent content analysis of an additional set of articles whose abstracts identify them as describing active learning pedagogies in practice. These articles included English-language abstracts from the Educational Resource Information Center (ERIC) over a ten-year period (including 2007 to 2015). ERIC was selected as it is considered to have top Education database that compiles a wide array of resources including scholarly journals, magazines, and other informal resources for all levels and topics of education.

To be as inclusive and representative as possible the ERIC database search included: peer and non-peer reviewed journal articles, reports, guides, opinion papers, teacher blogs, dissertations/theses, numerical/qualitative data, digests, and reference materials. Articles identified were then limited to those describing K-8 (primary and secondary) education and those pertaining to: discovery-based learning, case-based learning, active learning, inquiry-based learning, problem-based learning, and project-based learning. All the articles meeting the above criteria, 116 in total, were then logged and coded. They comprised published manuals, kits, and journal articles, both peer- and non-peer-reviewed. This decision was made to be as inclusive of different voices as possible and incorporate practical examples and explanations that are typically left out of academic literature. A review of all 116 article abstracts was conducted, and 45 total articles were identified which described an active learning pedagogy in theory or practice, referring to a K-8 learning environment, and published between 2007 and 2015 .

Initial patterns emerged during article coding, including: articles either described an entire school devoted to active learning pedagogies, combination/interdisciplinary classrooms with an active learning approach, or a kit to help educators conduct project, problem or inquiry based learning lessons (i.e. a teaching method). Therefore, the articles were divided according to two categories: pedagogy described and type of content. The articles are listed in Table 2. The process was completed through a double coding process with an interrater reliability of $70 \%$, which was resolved through discussion and coded a second time once a consensus code was selected.

To compare the findings of the comparative analysis and the content analysis, the 45 articles were then graded on an averaged Likert scale, where the articles with the most constructivist elements were given a higher score. Case studies describing active learning schools were assigned a value of 5 , as they were the most closely aligned with the constructivist paradigm and pedagogical designs described in the comparative analysis; interdisciplinary classrooms were assigned a value of 3 as they explained pedagogy in practice with constructivist terms; and classrooms using projects, problems and inquiries as teaching methods or tools, were given a value of 1 . The outcome was four ranked pedagogies, since discovery-based learning was not represented in the articles selected from the ERIC database. The implications of this ranking of pedagogies, from the comparative and content analysis, are then discussed in the final section.

\subsection{Limitations}

The strength of the traditional and systematic literature reviews lies in the articles selected and/or identified. Irrespective of the type, a limitation when it comes to completing a literature review is that it can never be all encompassing. Also, the sampling of articles and the coding of words both have normative implications which can rarely be overcome. While some might find these articles to be representative of some or all the pedagogies, others will not. In any case, it is beyond the scope of this article to conclude "once-and-for-all" the philosophical tenants of each of these theories in a way that is agreeable to every one of them. However, this article aims to identify the usefulness of classifying pedagogies, particularly with constructivist elements.

In respect to the content analysis, the limitation of only using one database is that it may only offer a limited view of a topic. However, this limitation is overcome by increasing the article sample to include all types of content, thus allowing for a multitude of results and voices be presented in the literature. By conducting both a comparative and content analysis, in turn informed by two literature reviews, and providing a list of the articles sampled, this paper aims to ameliorate the situation with regard to the aforesaid limitation.

\section{COMPARATIVE ANALYSIS OF ACTIVE LEARNING PEDAGOGIES IN THEORY}

The theoretical foundations of different active learning pedagogies are difficult to flesh out as they are often used interchangeably and without clear definition (Savery, 2006). What one researcher or teacher may call inquiry based learning, may function more like problem based learning for another. As active learning pedagogies are typically understood to belong to the constructivist epistemology, or way of understanding knowledge and how we create it, this paper uses comparative markers to distinguish the pedagogies from one another. The following section will describe constructivism, how it informs active learning pedagogies, and the essential elements with which pedagogies will be compared. The remainder of the section, informed by a traditional literature review, will detail and categorize five pedagogies identified by Jonassen (1991) as constructivist active pedagogies (namely, those structured around problem-based, discovery-based, inquiry-based, project-based and case-based learning), with respect to six elements of constructivism (more precisely, learner-centeredness, focus on process and content; use of interdisciplinary lessons; use of collaborative lessons; focus on student reflection; and importance of intrinsic motivation depicted as lack of emphasis on assessment).

\subsection{Constructivism}

Paulo Freire, educational theorist credited as a founder of constructivism, argued that education should be about learning not teaching; learning as in a place where individuals construct their 
own knowledge personally and socially (Freire, 1993; Jonassen, 1999; Wertsch, 1997). In schools that adhere to the constructivist epistemology, the focus shifts to students' behavior (Michael, 2006) and learning process (Jonassen, 1999). Teachers remain integral; however, their role vacillates between expert, guide, and facilitator (Haberman, 1991; Wyness, 1999), and learning rather than teaching becomes center point.

Constructivist learning environments require: student work that is intrinsically motivating to them; learners reaching a certain level of self-directedness; and teachers who provide support (scaffolding), context, relevance, and constant feedback. In these environments learners are encouraged to build on prior knowledge, think critically, reflect, and present their information independently and in small groups. As students' capacity increases they become responsible for both the content and process of learning, which frees up the teacher to play a non-expert, facilitator, or guiding role. Grading becomes replaced by self and peer evaluation, which shifts the educational focus from an intrinsic experience to another intrinsic one and increases student's motivation to be self-directed in the long term (Furtak, Seidel, Iverson, \& Briggs, 2012; Michael, 2006; Michael \& Modell, 2003 Norman and Schmidt, 1992)

While critics of constructivism argue that intense student engagement could potentially tax learner's working memory and thwart long-term memory processes (Kirschner et al., 2006; Mayer, 2004; Michael, 2006), this criticism has come under fire for lacking empirical evidence to support its claims (Talheimer, 2010). Conversely, evidence has been presented that suggests increased student engagement, through more active learning pedagogies, effectively increases knowledge transfer between disciplines (Norman and Schmidt, 1992) and promotes longterm memory retention (Hmelo-Silver, Duncan, \& Chinn, 2007; Schmidt, Loyens, Van Gog, \& Paas, 2007). Any issues of taxing student's working memory are resolved by a combination of scaffolding and curricula design methods made by teachers that are respectful of learners' prior knowledge and experience (Savory, 2006; Vosniadou et al, 2001; Vygotsky, 1978).

While not meaning to oversimplify the constructivism epistemology, parsing out elements of the epistemology that may be useful in comparing the five active learning pedagogies include: requirements of learner-centeredness (i.e. knowledge creation over knowledge provision); the focus on process and content; interdisciplinary lessons; collaborative lessons; a focus on student reflection; and the importance in intrinsically motivating student work as depicted by a lack of focus on assessment. Using these elements as a guide, the remainder of the section describes the five active learning pedagogies.

\subsection{Problem-Based Learning}

Problem-based learning (PBL) is a popular active learning pedagogy which fits into the constructivist educational paradigm as both a curriculum and a learning philosophy (Maudsley, 1999; Savery, 2006). Maudsley (1999) describes PBL as an environment where "knowledge is acquired, synthesized, and appraised out of working through and reflecting upon -in facilitated small group work and self-directed learning -a progressive and stimulating framework of context-setting problems" (p. 182).

Developing problem solving skills is essential to the Problem-based learning environment, as well as, developing research skills and empowering learners to "integrate theory and practice, and apply knowledge and skills to develop a viable solution to a defined problem" (Savory, 2006, p. 9). Problems in PBL are ill-structured, ill-defined, unresolved or puzzling (Barrows \&
Tamblyn, 1980); in need of some explanation, correction (Dolemans \& Schmidt, 1994), new information (Norman, 1988), or analysis to be settled (Walton \& Matthews, 1989).

PBL has been criticized as a curriculum that is often designed and implemented poorly, and a pedagogy that lacks objective-aligned assessment methods (Boud \& Feletti, 1997). Moreover, cognitive science critics add that problem-solving skills are probably not teachable and therefore a core goal of PBL may be impossible to achieve (Kirschner, Sweller \& Clark, 2006; Maudsley, 1999; Norman and Schmidt, 1992). Further research suggests that, without proper scaffolding, consistent feedback, or context, students in PBL classrooms have shown less progress than students in traditional classrooms (Norman \& Schmidt, 1992; Savery, 2006). Ultimately, these criticisms of implementation ineffectiveness and not providing support for novice and naïve learners, are outdated and overshadowed by more recent research that shows when implemented with fidelity, active learning pedagogies are equally and sometimes more effective than traditional teaching methods (Albanese \& Mitchell, 1993; Denton, Adams, Blatt \& Lorish, 2000; Hmelo-Silver et al., 2007; Schmidt et al., 2007; Torp \& Sage, 2000; Vernon and Blake, 1993). Problem-solving skills -supporters of active learning pedagogies argue- can be taught through an experiential learning process that PBL can provide when implemented with fidelity.

Summing up, PBL consequently describes a pedagogy where learners use the process of problem solving through self-directed and/or group research to explore and solve various types of problems in need of solutions. Frequent descriptive feedback, learner reflection and an effort to design learning environments to intrinsically motivate students are essential elements (Hmelo et al., 2007). Regarding constructivist elements, PBL places an importance on learner-centered, process oriented environments that utilize collaborative methods, reflection, and self-assessment as an indicator of intrinsically motivating learning. While described as benefits of PBL, content transferability and an emphasis on content knowledge are not explicitly listed as integral elements of implementing PBL (see Table 1 for ranking at the end of this section).

\subsection{Discovery-Based Learning}

Jerome Bruner is credited with the development of the Discovery-based learning pedagogy. Although other educational philosophers influenced its construction, including Seymour Papert, it is Bruner's article The Act of Discovery (1961) that sparked research into discovery as a constructivist pedagogy (Mayer, 2004). Bruner argues that the goal of education is to develop content knowledge, but also to help each learner become an "autonomous and self-propelled ... thinker", who has a love and capacity for learning after formal schooling (1961, p. 2). Bruner hypothesizes that by learning through discovery, students will develop an "intellectual property" or ownership over their own learning as they continue to discover and create knowledge (pp. 2-4). This is counter to current models of education which have an "outer-directedness", Bruner argues, that focuses on extrinsically motivating students with punishments (e.g. detention, suspension, and expulsion) and rewards (amongst them, grades, awards, trophies and scholarships, to name a few). Discovery learning, therefore, should focus on identifying an "inner-directedness", or intrinsic motivation for learning, for each student (p. 7).

This intrinsic motivation for student learning, as Bruner explains, is also important in developing skillsets to inquire, discover, and solve problems; therefore, schooling should be set up to maximize student experience. Additionally, Willis (2006) sug- 
gests learner interest and engagement is paramount for long-term knowledge retention (pp. 8-9).

The focus on discovery-based learning, therefore, is about the student's exploration of their environment through manipulation, experimentation, and wrestling with interesting issues (Ormrod, 1995), in an environment that acknowledges limitations of prior knowledge and capacities for inquiry (Schmidt et al., 2007). Unlike PBL, the process of discovery-based learning does not require educational objectives or development of specific skill-sets. Methods of discovery are directed by the student and can range from experiments (van Joolingen, 1999), individual and collective problem solving, or individual inquiry and research (Borthick \& Jones, 2000).

In its purest form, discovery-based learning is a student directed knowledge creation process with boundaries defined by the student. However, these elements also describe the main critiques of the pedagogy: a lack of teacher support, teacher guidance, content focus or learning objectives. The same as in PBL, the most successful cases of discovery-based learning have been associated with learners who have prior content knowledge, are guided as a means of scaffolding content and skill, and where the pedagogy is first applied in a structured manner (Mayer, 2004; Roblyer \& Erlanger, 1998). Most supporters of discovery-based learning acknowledge the need for teacher guidance and curricular and process bounds, especially for naïve learners; it is recommended that pure Discovery learning be reserved for expert knowledge explorers with extensive experience and expertise. Teacher guidance includes context setting, instruction and modelling of methods, and provision of content information including "manuals, simulations, feedback, and example problems" (Alfieri, Brooks \& Aldrich, 2011, p. 2).

In terms of classifying Discovery learning based on constructivist elements, student involvement is high, placing significant importance on learner centeredness. Equally important are process and intrinsic self-assessment. Discussed, but not explicitly stated as integral to the pedagogy, is the development of specific content knowledge, content transferability, collaborative methods, and self-reflection.

\subsection{Inquiry-Based Learning}

Inquiry-based learning (IBL) is often associated with the adage, "Tell me and I forget, show me and I remember, involve me and I understand" (Escalante, 2013). Savery (2006) describes IBL as "activities which begin with a question followed by investigating solutions, creating new knowledge as information is gathered and understood, discussing discoveries and experiences, and reflecting on new-found knowledge" (p. 16). In most instances, the process of IBL closely follows the steps of the scientific method and is most often referenced as a model used in science education efforts.

Where problems drive learning in Problem-based learning, Owens, Hester, and Teale (2002) suggest that inquiry-based classrooms are driven by questions that focus and frame inquiries. Banchi and Bell (2008) describe four different inquiry stages that students with novice to expert levels of problem solving skills can accomplish: (1) confirmation; (2) structured; (3) guided; and (4) open. Confirmation tends to be reserved for novice problem solvers as it provides the maximum amount of teacher guidance and is described as a method rather than a pedagogy. In the confirmation stage, the teacher proposes a question, and recommends a process all within a specific context for the student, where answers or results are known (Owens et al., 2002). The introduction to inquiry and problem solving is the primary goal of confirmation inquiry (Banchi \& Bell, 2008).

Structured inquiry, in comparison, allows for inquiry with unknown results or answers; however, process and question are often predetermined by the teacher. Guided inquiry offers students more agency over process to find an unknown answer to a predetermined question. For confirmation, structured and guided inquiry, teachers continuously guide learning and give feedback in the course of the inquiry. In open inquiry, however, the students' process reaches an expert level of scientific inquiry, where they "act like scientists, deriving questions, designing and carrying out investigations, and communicating their results" (Banchi \& Bell, 2008, p. 27). In these environments, students propose their own questions, complete an investigation, identify and present previously unknown results or answers with minimal traditional teacher guidance and support. In sum, IBL is heavily focused on having the student reach a level of expertise in self-directed inquiry based on the scientific method: question formulation, investigation, solution development, response, discussion, and reflection on results (Bishop et al., 2006). Both student skill development and scientific process are integral.

Based on research in schools, Owens et al. (2002) report that effective inquiry-based learning encourages student curiosity, makes inquiry visible, emphasizes the importance of topics and questions, facilitates the process of gathering and presenting information, and integrates technology. IBL is highly focused on the process of learning, but also ensures that students are directing their learning and teachers are available to scaffold student capacities to move from a confirmation to an open inquiry skill stage (Bianchi \& Bell, 2008; Bishop et al., 2006; Owens et al., 2002). In terms of the constructivist scale, learner-centeredness, process, reflection, and self-assessment are integral aspects of IBL. While content knowledge is sometimes important, as well as its transferability and collaborative methods, they are described as benefits of IBL and not integral to its successful implementation.

\subsection{Project-Based Learning}

Project-based learning is an active learning style focused primarily on a specific student output: a project. Barron and Darling-Hammond (2008) describe project-based pedagogy as one that "involves completing complex tasks that typically result in a realistic product, event, or presentation to an audience" (p. 2). Thomas (2000) adds to this definition by suggesting there are five essential elements of project-based learning: (1) projects are the curriculum, not tools to supplement the curriculum (methods); (2) projects are instigated via driving questions or ill-defined problems; (3) students need to inquire, complete constructive investigations, and build knowledge; (4) learning needs to be student-driven, with teacher facilitation and guidance; and (5) projects must be intrinsically motivating or focus on issues of authentic interest to the students. Project-based learning, therefore, focuses on issues and problems affecting students and their communities, explored through an interdisciplinary lens, in a way that allows for knowledge transferability, in small collaborative groups, with authentic assessments (Barron and Darling-Hammond, 2008). While Barron and Darling-Hammond's definition suggests project-based learning would be implemented as a pedagogy, Savery (2006) argues, after examining project-based learning in practice, that projects are often used as a tool rather than a complete theory of learning (i.e. the project is more important than the inquiry or investigation process). 
In terms of the constructivist scale, project-based learning seeks to answer questions and solve problems; it has a primary focus on process but content knowledge is integral to the success of the project, as well; it should be student driven, and intrinsically motivated, but can also be used as a teaching method. Therefore, learner-centeredness, process and content, collaborative methods, reflection, and assessment are all important; only content transferability does not appear as an essential element of the pedagogy.

\subsection{Case-Based Learning}

Case-based learning (CBL) is described as a pedagogy that involves exploring, diagnosing, problem-solving and repeating to reach understanding (Maudsley, 1999; Thistlethwaite et al., 2012).

Cognitive science literature suggests that $\mathrm{CBL}$ is based on the idea of "case-based reasoning" which describes the process of recalling information, applying it to different contexts and then storing that new information (Riesbeck, 1996). This theory of cognitive reasoning suggests that when experiencing a new situation, our memory attempts to retrieve a similar case from our past to relate. We then adapt our previous experience and knowledge to work our way through the new situation. Lessons learned from the new experience are then attached to the previous experience and stored to be retrieved later. From these clusters of experience, we begin to develop a caseload (or index of cases) to which we can make connections and draw references. CBL attempts to work off this process of retrieving, adapting, applying, and then storing information.

Riesbeck (1996) suggests five principles that make case-based learning pedagogy effective: (1) provide experiential learning situations; (2) provide enough examples to develop a large caseload/index; (3) provide connections so that interdisciplinary links are made at the time of knowledge construction (to root out indexing problems); (4) not to penalize failure as it is a necessary part of learning; and (5) provide sufficient scaffolds for students to succeed. These lessons point to the value of expert knowledge, on-the-job training and life experience, via the teacher or other specialist in the classroom.

In CBL students "develop critical thinking skills, learning through decision-making and role-playing situations, increasing confidence in defining, confronting, analysing, and solving problems through interactive discussions, and exercising and developing skills in public speaking and group problem solving" (Foran, 2001, p. 45). Case-based learning seems to the be the most constructivist yet with more than 5 elements being integral to the success of its implementation: learner-centered, content, interdisciplinarity, collaborative learning, and reflection; and benefits of
CBL that were described but not predetermined by the pedagogy are the process of learning and student driven assessments.

\subsection{Summary of Active Learning Pedagogies Compared}

In this section, a traditional literature review was conducted to parse out the differences of five learning pedagogies based on identifying the importance of six constructivist elements. The cumulative findings are presented here in Table 1.

From this representation of the literature, readers could conclude that all five of the active learning pedagogies are learner-centered; students are the primary knowledge creators and focus of all the pedagogies, which is aligned with constructivist epistemology. The differences between the theories, therefore, lie on the descriptions of their focus on the other constructivist factors: process/content, interdisciplinary lessons, collaborative lessons, reflection, and assessment. Initially. it was the author's intention to rate these pedagogies on a scale of constructivism, in which by using Table 1 as an example we might place $\mathrm{CBL}$ as the most constructivist and discovery-based learning as the least constructivist one. CBL literature placed a large importance on 5 of the comparative indicators and discussed as elemental the other two indicators, giving them a total of 19 points on our Likert scale. In comparison, discovery-based learning articles described three factors as important, discussed two others and did not mention interdisciplinary focus or methods.

The problem with this scale, however, lies in the many degrees of constructivism the pedagogies encompass. Any adaptation from theory in practice would undoubtedly reorder the pedagogy's categorization and determine the classification unresolved (so, open ended inquiry of IBL would be the most constructivist pedagogy, and project-based learning, which only focuses on obtaining an output, could be the least constructivist one). Therefore, it is important to be considerate of the difference in theory and practice, and not hold one over the other.

Some conclusions we might be able to draw from this literature review, however, are that problem-based learning places the stress on process, collaborative learning, reflection, intrinsic motivation and assessment; discovery-based learning aims to provide lessons (content and process) that are inspired by student's intrinsic motivation; inquiry-based learning environments have a specific process of engaging students, but are also considerate of student intrinsic motivation and reflective processes; project-based learning focuses on creating an output: a project; and lastly, case-based learning details all elements as integral to this pedagogy's successful implementation.

Table 1. Comparing Active Learning Styles on Constructivist Elements

\begin{tabular}{rccccc}
\cline { 2 - 5 } & Case-based & Problem-based & Inquiry-based & Project-based & $\begin{array}{c}\text { Discovery- } \\
\text { based }\end{array}$ \\
\hline Learner-Centered & Important & Important & Important & Important & Important \\
Process & Discussed & Important & Important & Important & Important \\
Content & Important & Not Important & Discussed & Important & Not Important \\
Interdisciplinary & Important & Not Important & Not Important & Not Important & Discussed \\
Methods & Important & Important & Discussed & Discussed & Discussed \\
Reflection & Important & Important & Important & Important & Not Important \\
Assessment & Discussed & Important & Important & Important & Important \\
\hline Total & 19 & 15 & 16 & 17 & 13 \\
\hline
\end{tabular}

Note: Total figures calculated by assigning "Important" values of 3; "Discussed" values of 2; and "Not important" no points. 
The next section of this paper looks at a different body of literature, articles describing active learning pedagogies in practice, and through a critical lens examines similarities and differences between its findings and the ones presented in the section dedicated to the comparative analysis of active learning pedagogies in theory.

\section{CONTENT ANALYSIS OF ACTIVE LEARNING PEDAGOGIES IN PRACTICE}

The objective of the content analysis is to add another lens to our understanding of active learning pedagogies: a practical perspective. Through an organized process of identifying, narrowing and coding resources, a systematic literature review and content analysis was conducted.

Forty-five English-language abstracts of articles detailing active learning pedagogies in practice were double-coded and analyzed. Of thousands of articles that self-identify as describing active learning pedagogies, through a closer lens of those published within the last ten years (between 2007 and 2015), describing K-8 (primary and secondary) classrooms and schools, and focusing only on discovery-based learning, case-based learning, active learning, inquiry-based learning, problem-based learning and/or project-based learning, only 45 were identified.

The 45 identified articles were then coded based on the six constructivist elements, as well as other elements. Since only abstracts were coded, not all the six elements of constructivism were explicitly detailed. However, during the coding process patterns emerged which allowed for classification.
The articles were grouped according to several parameters: general descriptions about the pedagogies in practice (i.e. interdisciplinary or collaborative methods), the learning environments in which they are conducted (in other words, school-wide implementation being representative of strong constructivism), and/or how they may be used as tools or methods rather than complete pedagogical approaches in lessons (or expressed differently, used as a tool in a single lesson for a predetermined output).

While it was an initial goal to group the articles in the same categories as in the comparative analysis, this proved impossible. Therefore, the content analysis findings are presented in two parts: direction; and approaches. Direction discusses the coding for learner-centeredness, as it was shown in all 45 resources. Approaches then discusses the other five constructivist elements as they appeared in practical article abstracts.

\subsection{Direction: Student Directed or Teacher Guided}

To analyze the 45 articles through the learner-centered constructivist element the articles were coded using keywords including, but not limited to: student, teacher, guidance, minimal, led, student (led), engage(d), directed. The findings confirmed those of the comparative literature review according to which all five pedagogies are implemented with varying degrees of teacher support, undoubtedly as a response to learner naivety and inexperience.

The articles dedicated to IBL, for instance, described teachers as experts in two articles, as guides in five, as facilitators in two and teachers' roles were not detailed in four. Further research would be needed to determine whether a specific pedagogy, im-

Table 2. Articles Describing Active Learning in Practice: Schools and Classrooms

\begin{tabular}{|c|c|c|c|c|}
\hline \multirow[b]{2}{*}{ Schools } & Case-based & Problem-based & Inquiry-based & Project-based \\
\hline & & & $\begin{array}{l}\text { Gostev \& Weiss (2007); } \\
\text { Heid et al. (2009) }\end{array}$ & Realon (2012) \\
\hline $\begin{array}{l}\text { Interdisci-plinary Class- } \\
\text { rooms }\end{array}$ & & $\begin{array}{l}\text { Branson \& Thomson } \\
\text { (2013); Flores (2006); } \\
\text { Frazier \& Sterling (2007); } \\
\text { Hollen et al. (2011); } \\
\text { Inel \& Balim (2010); } \\
\text { Pedersen et al. (2009); } \\
\text { Samsonov et al. (2006); } \\
\text { Wieseman \& Cadwell } \\
\text { (2005) }\end{array}$ & $\begin{array}{l}\text { Larkin et al. (2012); } \\
\text { NASA (2007); Podoll et } \\
\text { al. (2008); Sang (2010); } \\
\text { Schinske et al. (2008) }\end{array}$ & $\begin{array}{l}\text { Educational Horizons } \\
\text { (2013); Nargund-Joshi } \\
\text { \& Lee (2013); Ha (2010); } \\
\text { Riskowski et al. (2010); } \\
\text { Selmer et al. (2014); } \\
\text { Verma et al. (2011) }\end{array}$ \\
\hline $\begin{array}{l}\text { Single Subject Classrooms } \\
\& \text { Packages for class units }\end{array}$ & Brand (2011) & $\begin{array}{l}\text { Atwood (2013); Barron } \\
\text { (2003); Cerullo (2003); } \\
\text { Gutierrez-Perez \& Pirrami } \\
\text { (2011); Kaldi et al. (2011); } \\
\text { Kreider (2008); Lee \& Bae } \\
\text { (2008); Liu et al. (2001); } \\
\text { Passow (2003); Smith \& } \\
\text { Owens (2003); Sterling \& } \\
\text { Hargrove (2012); Sterling } \\
\text { (2007); Tsoukalas (2012) } \\
\text { Tulloch \& Graff (2007); } \\
\text { Zhang et al. (2011) }\end{array}$ & $\begin{array}{l}\text { Abell \& Volkmann (2006); } \\
\text { Cords et al. (2012); Rumo- } \\
\text { hr (2013); Taasoobshirazi } \\
\text { et al. (2006); Wu \& Krajcik } \\
\text { (2006) }\end{array}$ & $\begin{array}{l}\text { Filippatou \& Kaldi (2010); } \\
\text { Lattimer \& Riordan (2011) }\end{array}$ \\
\hline Total Points & 1 & 39 & 30 & 25 \\
\hline Average Points per article & 1 & 1,69 & 2,75 & 2.77 \\
\hline
\end{tabular}

Note: Total points calculated by assigning "Schools" values of 5; "Interdisciplinary classrooms" values of 3; and "Single Subject Classroom" values of 1. The scores for each pedagogy are then averaged by the total 45 articles and presented as the average points per article. 
plemented with less (or more) student guidance is useful at each level of learning with less (or more) experienced students. This kind of analysis is beyond this scope of this paper.

\subsection{Approaches: Pedagogy or Method}

Coding articles for the other 5 elements of constructivism (process/content, interdisciplinarity, collaboration, reflection, and assessment), as well as, variations on these keywords did not return any results. However, patterns did emerge that we may take to be representative of some or all of the remaining constructivist elements, namely: articles that discussed accounts of school-wide active learning environments represented strong constructivist elements; articles depicting whole classes being devoted to interdisciplinary or collaborative active learning environments are indicative of a good constructivist connection; and classrooms where active learning pedagogies were used in lessons showed a weak constructivist connection. It is important here to note that these classifications do not suggest superiority. Classification merely suggests that whole schools have reached a higher level of student-directedness in comparison to classrooms or teachers using the pedagogy as a method to take the first steps towards self-guided learning.

In total, the 45 articles selected for the content analysis discussed an account of project-based, problem-based, inquiry-based, or case-based learning in a classroom or entire school. Three articles described schools implementing an active learning environment, 19 articles referred to subjects or courses taught on an interdisciplinary basis, and the final 22 articles showed lessons or methods used in a single course or subject (See Table 2 for the final breakdown).

Problem-based learning pedagogy evaluations represented 51\% of the articles sourced, accounting for 23 of the total 45 articles examined; inquiry-based learning examples made up 12 articles, or $27 \%$ of articles presented; project-based learning efforts were described in $20 \%$ or 9 of the articles sourced; CBL was shown in only $2 \%$, or 1 article presented; and discovery-based learning was hardly represented in the sampling. It remains unclear why discovery-based and case-based learning environments have such a low representation, however, what is clear is that half of the articles sourced described active learning as a method (that is, a tool, kit, or package) rather than a pedagogy (or expressed differently, an environment which takes into account both the theory and the practice of learning).

In respect to the patterns that emerged about the types of environments that were represented in the literature, the more comprehensive implementation of active learning receiving the most points and examples of specific lessons the least: (1) the school-wide application of active learning pedagogies was given 5 points; (2) the articles that described active learning pedagogies in interdisciplinary or collaborative classroom settings were given 3 points; and (3) articles that explained the use of active learning as a tool in a single subject or lesson (e.g., one science class) were assigned 1 point. The pedagogical sums were then totaled and averaged to counter the overrepresentation of certain pedagogies in the literature.

The findings gathered in Table 2 suggest that Problem-based learning was presented in the most articles in the sampling, though frequently described as a method rather than a pedagogy. Inquiry-based learning and project-based learning both have whole school and a multitude of interdisciplinary classroom examples, with less focus on single subject lessons, which made their representation more constructivist than the lesson-heavy examples of problem-based or case-based learning.
This section's content analysis aimed to determine whether the literature captures active learning pedagogies in practice in the same light as the theoretical literature. These were the findings: student or teacher directedness was a poor element to classify pedagogies as there are varying levels of guidance dependent on the student's needs; case-based and discovery-based learning had very low representations in the literature and were difficult to compare to other pedagogies in practice; and lastly, while problem-based learning made up a majority of observable and evaluative literature, it focused primarily on single lessons whereas project- and inquiry-learning articles represented implementation that could be described as more constructivist (i.e. whole classrooms and schools). Even though the goal was to be able to recreate Table 1 with the findings from the content analysis, in this selection of abstracts too many missing elements made this recreation impossible. The advantage of the content analysis over the comparative analysis, however, was its systematic nature which allowed for a weighting of articles based on their representation in the literature. This weighting allows us to better categorize the literature than with the comparative analysis. Lastly, creating a classification system through a traditional literature review based on theoretical articles provides markedly different results than completing a systematic literature review with article abstracts even when using the same comparative elements (i. e. constructivist principles).

\section{CONCLUSIONS}

The approach to learning, teaching and education offered by the constructivist epistemology is exemplified in active learning pedagogies (Jonassen, 1991). But the definitions, descriptions, evaluations, and outcomes of each of the pedagogies described in the literature remain intertwined (Prince, 2004). To determine whether one could untangle the pedagogies from one another, practically and theoretically, this article used traditional and systematic literature reviews to identify and analyze articles describing five active learning pedagogies. The articles were then coded and compared based on six constructivist elements. Our findings are presented in Tables 1 and 2 during the previous section.

There are many conclusions we can draw from the analyses performed in this article. For instance, the constructivist elements used as comparative indicators were helpful to distinguish pedagogies from one another in the theoretical lens, yet proved ineffective in the practical lens. Additionally, in both theoretical and practical examples, it is clear that each of these pedagogies are implemented with different degrees of learner-directedness according to the capacity of the teacher and the student, the nativity and experience of the latter, and other aspects. Therefore, a linear categorization may never be possible for these learning pedagogies; theory building will need to consider more diverse spectrums or more complicated scales. Another conclusion is that inquiry- and project-based learning pedagogies are presented in the literature as school-wide initiatives with higher student-directed environments, whereas the other pedagogies were detailed more often as tools or methods for more naïve or inexperienced learners. This conclusion reaffirms the recommendations for teacher scaffolding (as an expert, guide, or facilitator) at every level of learning towards a student-led learning approach (Savory, 2006; Vygotsky, 1978; Vosniadou et al., 2001).

Considering each of these contributions, practitioners may find this discussion on active learning pedagogies useful not only in comparing and contrasting pedagogies but also in recognizing their limitations to meet students' needs (e.g. classrooms with inexperienced or naïve learners may require less active methods). 
Future researchers will need to agree how to move forward with such a rift between theory and practice, evidence of differing degrees of student and teacher directedness, and identifying more recent publications of active learning pedagogy theory and practice where the ERIC database has lacks.

\section{REFERENCES}

Abell, S. K., \& Volkmann, M. J. (2006). Seamless Assessment in Science: A Guide for Elementary and Middle School. Arlington, VA: National Science Teachers Association.

Albanese, M. A., \& Mitchel, S. (1993). "Problem-based Learning: A Review of Literature on Its Outcomes and Implementation Issues.” Academic Medicine, 68(1), 52-80. doi:10.1097/00001888-199301000-00012

Alfieri, L., Brooks, P. J., \& Aldrich, N. J. (2011). Does Discovery-Based Instruction Enhance Learning? Journal of Educational Psychology Advance, 103(1), 1-18. doi:10.1037/a0021017

Atwood, P. (2013). Investigating the Climate System: WINDS. Winds at work. Problem-Based Classroom Modules. In Classroom Guide. National Aeronautics and Space Administration (NASA).

Banchi, H., \& Bell, R. (2008). The Many Levels of Inquiry. Science and Children, 46(2), 26-29.

Barron, B., \& Darling-Hammond, L. (2008). Teaching for meaningful learning: A review of research on inquiry-based and cooperative learning. San Francisco, CA: Jossey-Bass.

Barron, E. (2003). Energy: A Balancing Act. Investigating the Climate System. Problem-Based Classroom Modules. In Classroom Guide. National Aeronautics and Space Administration (NASA)

Barrows, H. S., \& Tamblyn, R. M. (1980). Problem-based learning: An approach to medical education. New York, NY: Springer.

Bishop, A., Bruce, B., Lunsford, K., Jones, M., Nazarova, M., Linderman, D., Won, M., Heidorn, P. B., Ramprakash, R., \& Brock, A. (2006). Supporting Community Inquiry with Digital Re-sources. Journal of Digital Information, 5(3).

Borthick, A. F., \& Jones, D. R. (2000). The motivation for collaborative discovery learning online and its application in an information systems assurance course. Issues in Accounting Education, 15(2), 181-210. doi:10.2308/iace.2000.15.2.181

Boud, D., \& Feletti, G. (1997). The challenge of problem-based learning. London: Kogan Page.

Brand, L. G. (2011). Evaluating the Effects of Medical Explorers, a Case Study Curriculum on Critical Thinking, Attitude toward Life Science, and Motivational Learning Strategies in Rural High School Students (Doctoral dissertation). Ball State University, Munice, Indiana (USA).

Branson, J., \& Thomson, D. (2013). Hands-on Learning in the Virtual World. Learning and Leading with Technology, 40(5), 18-21.

Bruner, J. S. (1961). The Act of Discovery. Harvard Education, 31, 21-32.

Cerullo, M. (2003). Investigating the Climate System: Precipitation 'The Irrational Inquirer.' Problem-Based Classroom Modules. In Classroom Guide. National Aeronautics and Space Administration (NASA).

Cords, N., Fischer, R., Euler, M., \& Prasad, A. (2012). Teaching Optics with an Intra-Curricular Kit Designed for Inquiry-Based Learning. Physics Education, 47(1), 69-72. doi:10.1088/0031-9120/47/1/69

Denton, B. G., Adams, C. C., Blatt, P. J., \& Lorish, C. D. (2000). Does the introduction of problem-based learning change graduate performance outcomes in a professional curriculum? Journal on Excellence in College Teaching, 11(2-3), 147-162.

Dolmans, D. H. S. M., \& Schmidt, H. G. (1994). What Drives the Student in Problem-based Learning? Medical Education, 28, 372-380. doi:10.1111/j.1365-2923.1994.tb02547.x

Educational Horizons. (1993). "The Hunger Games" and Project-Based Learning. Educational Horizons, 91(3), 24-27.

Eisenhardt, K. M., \& Graebner, M. E. (2007). "Theory Building from Cases: Opportunities and Challenges." Academy of Management Journal, 50(1), 25-32. doi:10.5465/AMJ.2007.24160888

Escalante, P. (2013). Inquiry-Based Learning in an English as a Foreign Language Class: A Proposal. Revista De Lenguas Modernas, 19, 479-485.

Filippatou, D., \& Kaldi. S. (2010). The Effectiveness of Project-Based Learning on Pupils with Learning Difficulties Regarding Academic Performance, Group Work and Motivation. International Journal of Special Education, 25(1), 17-26.

Finnish National Board of Education. (2015). Subject teaching in Finnish schools is not being abolished. Retrieved from http://www.oph.fi/english/current_issues

Flores, C. (2006). How to buy a car. Mathematics Teaching in the Middle School, 12(3), 161-164.

Foran, J. (2001). The Case Method and the Interactive Classroom. Thought and Action, $17(1), 41-50$.
Frazier, W. M., \& Sterling, D. R. (2007). Weather Tamers. Science Scope, 30(7), 26-31.

Freire, P. (1993). Pedagogy of the Oppressed. New York: Continuum Books.

Furtak, E. M., Seidel, T., Iverson, H., \& Briggs, D. C. (2012). Experimental and Quasi-Experimental Studies of Inquiry-Based Science Teaching: A Meta-Analysis. Review of Educational Research, 82(3), 300-329. doi: $10.3102 / 0034654312457206$

Gostev, M., \& Weiss, F. M. (2007). Firsthand Nature. Science and Children, 44(8), 48-51.

Gutierrez-Perez, J., \& Pirrami, F. (2011). Water as Focus of Problem-Based Learning: An Integrated Curricular Program for Environmental Education in Secondary School. US-China Education Review, A(2), 270-280.

Ha, Y. L. (2010). A Valuable Experience for Children: The Dim Sum and Chinese Restaurant Project. Early Childhood Research and Practice, 12(1), 1-12.

Haberman, M. (1991). The Pedagogy of Poverty Versus Good Teaching. Phi Delta Kappan, 7(3), 290-294.

Heid, K., Estabrook, M., \& Nostrant, C. (2009). Dancing with Line: Inquiry, Democracy, and Aesthetic Development as an Approach to Art Education. International Journal of Education and the Arts, 10(3), 1-21.

Hollen, S., Toney, J. L., Bisaccio, D., Haberstroh, K. M., \& Herbert, T. (2011). The Case of Lobster Shell Disease. Science and Children, 48(9), 54-59.

Hoon, C. (2013). Meta-Synthesis of Qualitative Case Studies. Organizational Research Methods, 16(4), 522-556. doi:10.1177/1094428113484969

Hmelo-Silver, C. E., Duncan, R. G., \& Chinn, C. A. (2007). Scaffolding and Achievement in Problem-Based and Inquiry Learning: A Response to Kirschner, Sweller, and Clark (2006). Educational Psychologist, 42(2), 99-107. doi:10.1080/00461520701263368

Inel, D., \& Balim, A. G. (2010). The Effects of Using Problem-Based Learning in Science and Technology Teaching upon Student's Academic Achievement and Levels of Structuring Concepts. Asia-Pacific Forum on Science Learning and Teaching, 11(2), 1-23.

Jonassen, D. H. (1991). Objectivism vs. constructivism: Do we need a new paradigm? Educational Technology Research and Development, 39(3), 5-14. doi:10.1007/BF02296434

Jonassen, D. H. (1999). Designing Constructivist Learning Environments. In C. M. Reigeluth (Ed.), Instructional-design Theories and Models: A New Paradigm of Instructional Theory (pp. 215-240). Mahwah, NJ: Lawrence Erlbaum Associates.

Kaldi, S., Filippatou, D., \& Govaris, C. (2011). Project-Based Learning in Primary Schools: Effects on Pupils' Learning and Attitudes. Education 3-13, 39(1), 3547. doi:10.1080/03004270903179538

Kirschner, P., Sweller, J., \& Clark, R. (2006). Why minimal guidance during instruction does not work: an analysis of the failure of constructivist, discovery, problem-based, experimental and inquiry-based teaching. Educational Psychologist, 40, 75-86. doi:10.1207/s15326985ep4102_1

Kreider, G. Y. (2008). Going on a Science Trek! Science Scope, 31(7), 36-40.

Larkin, D., King, D., \& Kidman, G. (2012). Connecting Indigenous Stories with Geology: Inquiry-Based Learning in a Middle Years Classroom. Teaching Science, 58(2), 41-46. Retrieved from the ERIC database. (EJ991268)

Lattimer, H., \& Riordan, R. (2011). Project-Based Learning Engages Students in Meaningful Work. Middle School Journal, 43(2), 18-23. doi:10.1080/00940771.2011.11461797

Lee, H., \& Bae, S. (2008). Issues in Implementing a Structured Problem-Based Learning Strategy in a Volcano Unit: A Case Study. International Journal of Science and Mathematics Education, 6(4), 655-676. doi: 10.1007/s10763-007-9067-x

Liu, M., Williams, D., \& Pedersen, S. (2001). Alien Rescue: A Problem-Based Hypermedia Learning Environment for Middle School Science. Journal of Educa tional Technology Systems, 30(3), 255-270.

Locke, E. A. (2007). The Case for Inductive Theory Building. Journal of Management, 33(6), 867-890. doi:10.1177/0149206307307636

Maudsley, G. (1999). Do We All Mean the Same Thing by 'Problem-based Learning'? A Review of the Concepts and a Formulation of the Ground Rules. Aca demic Medicine, 74(2), 178-185. doi:10.2190/X531-D6KE-NXVY-N6RE

Mayer, E. R. (2004). Should There Be a Three-Strikes Rule Against Pure Discovery Learning? The Case for Guided Methods of Instruction. American Psychological Association, 59(1), 14-19. doi:10.1037/0003-066X.59.1.14

Michael, J. (2006). Where's the evidence that active learning works? Advance in Physiology Education, 30, 159-167. doi:10.1152/advan.00053.2006

Michael J. A., \& Modell, H. I. (2003). Active Learning in Secondary and College Science Classrooms: A Working Model of Helping the Learning to Learn. Mahwah, NJ: Erlbaum.

Nargund-Joshi, V., \& Lee, J. S. (2013). How Much Trash Do You Trash? Science and Children, 50(7), 50-55. 
National Aeronautics and Space Administration (NASA). (2007). Field Trip to the Moon. Educator's Guide. In Classroom Guide. Washington, D. C.: National Aeronautics and Space Administration.

Norman, G. R. (1988). Problem-solving skills, solving problems, and problem-based learning. Medical Education, 22, 279-86. doi:10.1111/j.1365-2923.1988.tb00754.x

Norman, G. R., \& Schmidt, H. G. (1992). The Psychological Basis of Problem-based Learning: A Review of the Evidence. Academic Medicine, 67(9), 557-565. doi:10.1097/00001888-199209000-00002

Ormrod, J. (1995). Educational Psychology: Principles and Applications. Englewood Cliffs, NJ: Prentice-Hall.

Owens, R. F., Hester, J. L., \& Teale, W. H. (2002). Where do you want to go today/ Inquiry-based learning and technology integration? The Reading Teacher, 55(7), 616-625.

Passow, M. J. (2003). Investigating the Climate System: WEATHER. Global Awareness Tour. Problem-Based Classroom Modules. In Classroom Guide. National Aeronautics and Space Administration (NASA).

Pedersen, S., Arslanyilmaz, A., \& Williams, D. (2009). Teachers' Assessment-Related Local Adaptations of a Problem-Based Learning Module. Educational Technology Research and Development, 57(2), 229-249. doi:10.1007/s11423-007-9044-7

Podoll, A., Olson, B., Montplaisir, L., Schwert, D., McVicar, K., Comez, D. , \& Martin, W. (2008). Networking Antarctic Research Discoveries to a Science Classroom. Science Scope, 32(2), 30-33.

Prince, M. (2004). Does Active Learning Work? A Review of the Research. Journal of Eng. Education, 93(3), 223-231. doi:10.1002/j.2168-9830.2004.tb00809.x

Realon, M. S. (2012). They Keep Moving the Cheese: But Charlotte CTE Students Find Passionate Pathways to Prosperity. Techniques: Connecting Education and Careers, 87(7), 24-28.

Riesbeck, C. K. (1996). Case-based teaching and constructivism: Carpenters and tools. In B. G. Wilson (Ed.), Constructivist Learning Environments: Case Studies in Instructional. Englewood cliffs, NJ: Educational Technology.

Roblyer, M. D. \& Erlange, W. (1998). Preparing Internet-Ready Teachers. Learning and Leading with Technology, 26(4), 58-61.

Riskowski, J. L., Olbricht, G., \& Wilson, J. (2010). 100 Students. Mathematics Teaching in the Middle School, 15(6), 320-327.

Rumohr, F. (2013). Reflection and Inquiry in Stages of Learning Practice. Teaching Artist Journal, 11(4), 224-233. doi:10.1080/15411796.2013.815544

Samsonov, P., Pedersen, S., \& Hill, C. L. (2006). Using Problem-Based Learning Software with At-Risk Students: A Case Study. Computers in the Schools, 23(1), 111-124. doi:10.1300/J025v23n01_10

Sang, A. N. H. (2010). Plastic Bags and Environmental Pollution. Art Education, 63(6), 39-43.

Savery, J. R. (2006). Overview of Problem-based Learning: Definitions and Distinctions. Interdisciplinary Journal of Problem-based Learning, 1(1), 9-20. doi:10.7771/1541-5015.1002

Schinske, J. N., Clayman, K., Busch, A. K., \& Tanner, K. D. (2008). Teaching the Anatomy of a Scientific Journal Article. Science Teacher, 75(7), 49-56.

Schmidt, H. G., Loyens, M. M. S., Van Gog, T., \& Paas, F. (2007). Problem-based learning is compatible with human cognitive architecture: commentary on kirschner, sweller, and clark (2006). Educational Psychologist, 42, 91-97. doi:10.1080/00461520701263350

Selmer, S. J., Rye, J. A. , Malone, E., Fernandez, D., \& Trebino, K. (2014). What Should We Grow in Our School Garden to Sell at the Farmers' Market? Initiating Statistical Literacy through Science and Mathematics Integration. Science Activities: Classroom Projects and Curriculum Ideas, 51(1), 17-32. doi:10.1080/00368121.2013.860418

Smith, S. M., \& Owens, H. B. (2003). Clouds and the Earth's Radiant Energy System. Investigating the Climate System. Problem-Based Classroom Modules.In Classroom Guide, National Aeronautics and Space Administration (NASA).

Sterling, D. R. (2007). Methods and Strategies: Modeling Problem-Based Instruction. Science and Children, 45(4), 50-53.

Sterling, D. R., \& Hargrove, D.L. (2012). Is Your Soil Sick? Science and Children, $49(8), 51-55$.

Taasoobshirazi, G., Zuiker, S. J., Anderson, K. T. , \& Hickey, D.T. (2006). Enhancing Inquiry, Understanding, and Achievement in an Astronomy Multimedia Learning Environment. Journal of Science Education and Technology, 15(5), 383-395. doi:10.1007/s10956-006-9028-0

Talheimer, W. (2010). Cognitive Load Theory Coming Under Withering Attacks. Retrieved from http://www.willatworklearning.com

Thistlethwaite, J. E., Davies, D., Ekeocha, S., Kidd, J. M., MacDougall, C., Matthews, P., Purkis, J., \& Clay, D. (2012). The effectiveness of case-based learning in health professional education. A BEME systematic review: BEME Guide, 34(6), 421-444.

Thomas, J. W. (2000). A review of research on project-based learning. San Rafael, CA: The Autodesk Foundation.
Torp, L., \& Sage, S. (2002). Problems as possibilities: Problem-based learning for K-16 education. Alexandria, VA: Association for Supervision and Curriculum Development

Tsoukalas, J. M. (2012). Exploring Problem Based Learning to Promote 21st Century Learning Skills in Full Day Kindergarten. Minneapolis, MN: Walden University.

Tulloch, D., \& Graff, E. (2007). Green Map Exercises as an Avenue for Problem-Based Learning in a Data-Rich Environment. Journal of Geography, 106(6), 267-276. doi:10.1080/00221340701839741

Van Joolingen, W. (1999). Cognitive tools for discovery learning. International Journal of Artificial Intelligence in Education, 10, 385-397.

Verma, A. K., Dickerson, D., \&. McKinney, S. (2011). Engaging Students in STEM Careers with Project-Based Learning-MarineTech Project. Technology and Engineering Teacher, 71(1), 25-31.

Vernon, D. T. A., \& Blake, R. L. (1993). Does problem-based learning work? A meta-analysis of evaluation research. Academic Medicine, 68(7), 550-563. doi:10.1097/00001888-199307000-00015

Vosniadou, S., Ioannides, C., Dimitrakopoulou, A., \& Papademetriou, E. (2001). Designing learning environments to promote conceptual change in science. Learning and Instruction, 11, 381-419. doi:10.1016/S0959-4752(00)00038-4

Vygotsky, L. (1978). Interaction between learning and development. In M. Gauvain \& M. Cole (Eds.), Readings on the Development of Children (pp. 29-36). New York, NY: W. H. Freeman and Company.

Walton, H. J., \& Matthews, M. B. (1989). Essentials of problem-based learning. Medical Education, 23, 542-558. doi:10.1111/j.1365-2923.1989.tb01581.x

Wertsch, J. V. (1997). Vygotsky and the formation of the mind. Cambridge, MA.

Wieseman, K. C., \& Cadwell, D. (2005). Local History and Problem-Based Learning. Social Studies and the Young Learner, 18(1), 11-14.

Willis, J. (2006). Research-Based Strategies to Ignite Student Learning: Insights from a Neurologist and Classroom Teacher. Alexandria, VA: Association for Supervision and Curriculum Development.

Wu, H., \& Krajcik, J. S. (2006). Inscriptional Practices in Two Inquiry-Based Classrooms: A Case Study of Seventh Graders' Use of Data Tables and Graphs. Journal of Research in Science Teaching, 43(1), 63-95. doi:10.1002/tea.20092

Wyness, M. G. (1999). Childhood, Agency and Education Reform. Childhood: A Global Journal of Child Research, 6(3), 353-368. doi:10.1177/0907568299006003004

Zhang, M., Parker, J., Eberhardt, J., \& Passalacqua, S. (2011). What's so Terrible about Swallowing an Apple Seed?' Problem-Based Learning in Kindergarten. Journal of Science Education and Technology, 20(5), 468-481. doi:10.1007/s10956-011-9309-0

How to cite this article: Cattaneo, H. (2017). Telling Active Learning Pedagogies Apart: from theory to practice. Journal of New Approaches in Educational Research, 6(1), 144-152. doi: 10.7821/naer.2017.7.237 